\title{
Oral Signs of Helicobacter Pylori- Review of Clinical Outcomes
}

\author{
Damla Aksit Bicak*1 and Serap Akyuz ${ }^{2}$ \\ ${ }^{1}$ Near East University, Faculty of Dentistry, Department of Pediatric Dentistry, Mersin 10 Turkey \\ ${ }^{2}$ Marmara University, Faculty of Dentistry, Department of Pediatric Dentistry, Turkey
}

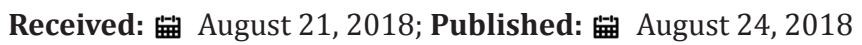

*Corresponding author: Damla Aksit Bicak, Near East University, Faculty of Dentistry, Department of Pediatric Dentistry, Near East Boulevard, ZIP: 99138, Mersin 10 - Turkey

\begin{abstract}
Helicobacter pylori (H. pylori) infection is the most common chronic bacterial infection worldwide and it plays a very important role in the pathogenesis of peptic ulcer, gastric carcinoma, and lymphoid tissue lymphoma. High reinfection rates after successful eradication treatments make the oral cavity a possible reservoir area for the survival of the bacterium. Therefore, the relationship between $H$. pylori and oral/gastric diseases is being investigated and has become a remarkable issue in recent years. In the oral cavity, $H$. pylori was first isolated from a dental plaque sample of a patient with gastric $H$. pylori in 1989. Investigation into the relationship of $H$. pylori with oral diseases has shown that oral $H$. pylori may cause halitosis, glossitis, recurrent aphthous stomatitis and dental caries. Hence, the aim of this review is to demonstrate the relationship between $H$ pylori and oral diseases in the context of the previous/latest research.
\end{abstract}

Keywords: Helicobacter Pylori; Dental Plaque; Saliva; Halitosis; Oral Diseases

Abbreviations: PCR: Polymerase Chain Reaction; VSC: Volatile Sulfur Compounds; P. gingivalis: Porphyromonas Gingivalis; T. denticola: Treponema Denticola; T. forsythia: Tannerella Forsythia; P. intermedia: Prevotella Intermedia; RAU: Recurrent Aphthous Ulcers; RAS: Recurrent Aphthous Stomatitis; H. pylori: Helicobacter Pylori

\section{Introduction}

Helicobacter pylori (H. pylori) is a spiral-shaped, gram-negative, urease-producing and highly pathogenic microaerophilic bacteria which causes development of highly serious gastrointestinal disorders and is mainly acquired in childhood [1-4]. Almost $50 \%$ of the global population is affected by the gastric $H$. pylori infection. The infection is more prevalent in developing countries in comparison to developed nations [5]. The prevalence of $H$. pylori infection mainly depends on age, geographic area and ethnicity [6]. Low levels of education and low socioeconomic status lead to an increase in the prevalence of $H$. pylori [7]. Although the pathway of transmission of $H$. pylori is not completely known, it is thought that the transmission could occur by faecal-oral, oral-oral or iatrogenic routes. Diarrhea is often seen in childhood and the transmission of $H$. pylori from the feces to the mouth can be accomplished by sharing infected toys or foods. Additionally, the detection of $H$. pylori in the breast milk suggests that the organism can move through the fingers or nipples to the breast and contaminate the milk. The fecaloral route of transmission seems to be possible only when there is close contact with infected individuals.

Gastro-oral transmission can occur through vomiting and gastrooesophageal reflux. Infection can occur through ingestion of food or exposure to vomit-infected objects colonized by H. Pylori. Oral-oral transmission can occur either permanently or temporarily through the dental plaque and saliva. The findings on identical strains of $H$. Pylori in the mouth and stomach strengthen the hypothesis that the oral cavity may be a reservoir for the bacteria. Close person-toperson contact between members of the same family can promote oral-oral transmission. Another mechanism for the oral-oral mode of transmission is through kissing. However, this appears to be an unlikely route of transmission. The increased prevalence of $\mathrm{H}$. pylori in the presence of crowded living conditions and poor self-care has also been reported. The higher prevalence of the infection among children whose mothers chew or taste their food before feeding them demonstrates that saliva could be a transmitter medium of the infection [8]. Also, H. pylori-like organisms can be seen in other animals, where infections with Helicobacter species have been reported in dogs and cats [9].

\section{Oral Cavity as an Extra Gastric Reservoir Area for $\boldsymbol{H}$. Pylori Survival}

The oral cavity, which is the entrance of the gastrointestinal system, has a complex flora including 350 different species. The oral temperature varies between $35-37^{\circ} \mathrm{C}$, which provides an ideal environment for the growth of $H$. pylori. Also, dental plaque has a low oxidation-reduction potential and this environment enhances the 
reproduction of facultative anaerobic bacteria, suggesting that the acidic $\mathrm{pH}$ resulting from the fermentation of carbohydrates creates a very favorable environment for the reproduction of $H$. pylori as a microaerophilic bacterium [10]. H. pylori was also detected in periodontal pockets of patients with periodontal diseases, on the dorsum of the tongue and in saliva samples $[1,11]$.

\section{Detection of Oral H. Pylori}

Cytology, urease test, culture, and polymerase chain reaction (PCR) are the methods used for the detection of H. pylori from dental plaque and saliva samples [5]. The use of the urease test for the detection of the H. pylori infection in the oral cavity shows low sensitivity due to the presence of a wide variety of bacteria with urease activity in the oral cavity. Streptococcus, actinomycetes and Hemophilus species are some of the urease active bacteria in the oral cavity. For this reason, the urease test is not a suitable method for H. pylori detection in the oral cavity [3]. While histological methods using classical hematoxylin and eosin staining methods can be used to visualize H. pylori, the use of Warthin-Starry and Giemsa staining can enhance the histological identification of microorganisms. Antimicrobial susceptibility tests can be performed using culture methods. Serological tests detect levels of antibodies such as IgG and IgA in serum raised in response to an infection of $H$. pylori.

A number of different PCR methods have been developed for the diagnosis of $H$. pylori infection, which can help to differentiate H. pylori strains [9]. Currently, there is no gold standard method for isolating $H$. pylori from the oral cavity, but it is stated that the best method for the detection of $H$. pylori from dental plaque is the PCR method. The use of molecular methods for the detection of bacteria is becoming increasingly widespread because of the difficulties in culturing bacteria other than gastric mucosa and the necessity of using non-invasive methods [5]. The results of the PCR method need to be examined very carefully as differences in the primers and the genes used in the amplification can affect the results [12].

\section{Helicobacter Pylori in the Dental Plaque and Saliva}

The presence of $H$. pylori in the dental plaque and saliva has been investigated in many studies [2,12-25]. The studies conducted thus far with the aim finding an association between oral and gastric H. pylori infection have demonstrated conflicting results. Burgers et al. [13] and Song et al. [24,25] conducted a study to determine the association between oral $H$. pylori and gastric H. Pylori. Both of the researchers detected oral $H$. pylori in the dental plaque and saliva samples of gastric $H$. pylori negative patients. Therefore, they stated that H. pylori may be present in the oral cavity independently from the gastric colonization and may belong to the normal oral flora. Valtez-Gonzales et al. [17] received dental plaque samples from 40 healthy children with no dyspepsia between the ages of 2-11 and examined the presence of $H$. pylori. In total, 35\% of these children showed the presence of $H$. pylori in dental plaque samples. In this study, it was demostrated that the oral cavity of children, particularly dental plaque, may be a reservoir area for $H$. pylori. Rasmussen et al. [18] attempted to demonstrate the presence of H. pylori in the oral cavity and the association between oral and gastric presence of the bacterium. A total of 78 adult patients with continuous abdominal pain were included in their study. At the same time, dental plaque and saliva samples were received from patients before each endoscopic procedure and examined with PCR. The investigators found an $H$. pylori prevalence rate of 70\% among saliva and dental plaque samples. Finally, the researchers reported a significant association between gastric and oral H. pylori. Liu et al. [19] conducted a study to examine the prevalence of oral $H$. pylori in the Chinese population and the incidence of gastric infection among patients with oral $H$. pylori. Out of the total of 443 adult patients with dyspeptic complaints, 263 (59.4\%) had H. pylori in their dental plaque samples and 273 (61.6\%) had gastric H. pylori. Gastric infection was found to be significantly higher in patients with oral H. pylori. Investigators found a strong association between the presence of oral/ gastric H. pylori, indicating that the oral cavity is an important reservoir for this pathogenic microorganism.

Tiwari et al. [20] received saliva samples from 80 patients suffering from dyspepsia and 20 healthy adult control groups. Seventy-two of the 80 dyspeptic patients (90\%) had gastric $H$. pylori. In saliva samples, $H$. pylori was detected in $70(87.5 \%)$ of the 80 dyspeptic patients and in $12(60 \%)$ of the 20 healthy individuals that constituted the control group. Since the investigators detected high levels of $H$. pylori in saliva samples, they noted that saliva has an important role in bacterial infection and may cause re-infections. Assumpçao et al. [2] included 99 dyspeptic adult patients in their study. A total of 95 patients (96\%) were found to be gastric $H$. pylori positive. Furthermore, H. pylori was not detected in the dental plaque specimens of any patient without gastric $H$. pylori. The researchers found a correlation between gastric colonization and oral colonization of $H$. pylori. Bickley et al. [21] received dental plaque and saliva samples from 14 patients before endoscopy and investigated the presence of urease $\mathrm{C}$ gene of $H$. pylori. The investigators were unable to detect $H$. pylori in any dental plaque and saliva samples.

Hardo et al. [22] examined dental plaque specimens from 62 adult patients with dyspepsia. They reported an $H$. pylori detection rate of $1.6 \%$ in dental plaque samples. No $H$. pylori was detected in any of the dental plaque samples of 61 patients. Hence, the researchers were unable to show a relationship between the presence of gastric H. pylori and oral H. pylori. Li et al. [23] received saliva samples from 56 patients with dyspeptic complaints and 40 patients were found to be gastric $H$. pylori positive. Among these patients, $30(75 \%)$ of them had H. pylori in their saliva samples. $H$. pylori was detected in the saliva samples of 3 gastric $H$. pylori negative patients. The researchers did not find a clear relationship between the gastric colonization of $H$. pylori and the presence of $H$. pylori in saliva. Bharath et al. [16] investigated the genetic presence of the bacterial urease gene using the real-time PCR method among both adult and pediatric patients aged between 10 and 80 years who had dyspeptic complaints. Six of the 56 patients had H. pylori in the supragingival dental plaque, while none of the patients had $H$. pylori in gastric biopsy specimens. The researchers suggested that patients may have previously received eradication therapy which was the cause of these outcomes and that this treatment was able to eradicate $H$. pylori in the gastric mucosa but was not effective on the dental plaque. 


\section{H. Pylori and Halitosis}

H. pylori has an important role in the gastrointestinal diseases that cause halitosis. With the oral colonization of $H$. pylori, the prevalence of volatile sulfur compounds (VSCs) producing periodontopathic microorganisms, such as Porphyromonas gingivalis ( $P$. gingivalis), Treponema denticola (T. denticola), Tannerella forsythia ( $T$. forsythia), Prevotella intermedia ( $P$. intermedia) are increased [26-28]. On the other hand, Suzuki et al. [26] indicated that the presence of $H$. pylori in the oral cavity may be associated with halitosis caused by periodontal pocketing and inflammation, rather than the bacteria's VSCs producing ability. The researchers found that the prevalence of $P$. intermedia was higher among the $H$. pylori-positive patients, while the prevalence of $P$. gingivalis and T. denticola was independent from the presence of $H$. pylori in the patients with periodontal symptoms. P. intermedia was detected in various parts of the oral cavity, including supragingival plaque, periodontal pockets, and the dorsum of the tongue. Katsinelos et al. [29] found a positive relationship between the presence of gastric $H$. pylori and halitosis according to the results of organoleptic measuring. The researchers reported that halitosis decreased after the eradication therapy. Chen et al. [30] conducted a subjective halitosis assessment with the organoleptic method and found that patients with gastric H. pylori were more likely to have halitosis than those without halitosis. Schubert et al. and other researchers [31-34], performed subjective halitosis assessment using the organoleptic method and could not demonstrate a relationship between the presence of gastric $H$. pylori and halitosis.

\section{H. Pylori and Oral Diseases}

Recurrent aphthous ulcers (RAU) are a common disease characterized by the periodic development of painful, single or multiple ulcerations in the oral mucosa. The symptoms of immunocompromised individuals are even more severe. Several possible etiologic factors have been proposed, including focal stimulation of mucosal T-cell functions by endogenous (autoimmune) or exogenous (hyperimmune) antigens. However, evidence of important causal factors is still lacking; for this reason, treatment of RAU with current methods is insufficient and is usually palliative [35]. Previous studies [35-38] have shown an increase in the formation of aphthous ulcers in the oral cavity with the presence of oral H. pylori. Also, there have been studies investigating the relationship between oral $H$. pylori presence and other mucosal lesions [39-42]. Iamaroon et al. [43] studied the effects of $H$. pylori in the etiology of RAU formation. They examined the surface of ulcerations and the dorsum of the tongue of 22 patients with RAU, and the dorsum of the tongue of 15 healthy subjects as a control group. The researchers stated that $H$. pylori is not involved in the pathogenesis of RAU. However, they indicated that the tongue dorsum may be a reservoir area for H. pylori.

Adler et al., [44] reported that glossitis was seen more frequently in patients who had gastric $H$. pylori Gall-Troselj et al. [45] found that glossitis and burning mouth syndrome were more common in the presence of H. pylori. Tiomny et al. and other researches $[27,46,47]$, reported that the incidence of recurrent aphthous stomatitis (RAS) increases in the presence of $H$.pylori.
Iamaroon et al. $[43,48]$ demonstrated that RAS was not associated with H. pylori Mansour-Ghanaei et al. [48] were only able to isolate H. pylori from one oral aphthous lesion thus, they were unable to demonstrate a relationship between a positive H. pylori ELISA test and the presence of $H$. pylori in RAS lesions. Iamaroon et al. [43] investigated the association of $H$. pylori and RAS by using a highly sensitive technique, nested PCR, in 22 patients with RAS with ages ranging from 12-36 years. Samples were taken from the lesions and the dorsum of the tongue of each patient. Additionally, samples from the dorsum of the tongue of 15 healthy individuals with ages ranging from 13-40 years who were taken as controls. The results showed that only one sample from a lesion (4.5\%) and one sample from the tongue $(4.5 \%)$ of two different patients with RAS were positive for $H$. pylori. In the control group, only 3 samples (20\%) were positive for $H$. pylori. These findings suggest that $H$. pylori does not play a role in the pathogenesis of RAS and the dorsum of the tongue may be a reservoir of H. pylori in some individuals.

\section{H. Pylori \& Caries, Oral Hygiene Habits, and Periodontal Health}

The relationship between periodontal health and oral/gastric $H$. pylori has been studied in many studies [3,19,49-61]. The association between periodontal disease and H. pylori infection was tested in a case-control study among 134 dyspeptic patients presenting for upper gastrointestinal endoscopy [50]. The periodontal status of the patients was evaluated as diseased or healthy. Among the cases, 30 subjects out of $65(46.2 \%)$ had periodontal disease compared to only 20 out of 69 (29\%) in comparison to the controls. Although the univariate analysis suggested that the relationship was significant, when analyzed by logistic regression, the difference was found to be insignificant. Silva et al. [54] reported that periodontal health was worse in the presence of oral H. pylori . However, the researchers did not find a significant association between the presence of gastric H. pylori and periodontal health. Al-Asqah et al. [49] examined 62 patients with a gingivoperiodontal disease and 39 patients with dyspeptic complaints without a gingivoperiodontal disease. They reported that $60 \%(37 / 62)$ of the periodontitis patients had gastric H. pylori compared to only $33 \%$ (13/39) of the patients without periodontitis. Furthermore, they reported that the prevalence of $H$. pylori in the dental plaque was higher among periodontitis patients $(79 \%, 49 / 62)$ than in patients without periodontitis $(43 \%$, 17/39). They also reported that the presence of the bacterium in both locations was higher among periodontitis patients (46.8\%, $29 / 62)$ than in patients without periodontitis $(10.3 \%, 4 / 39)$. The researchers demonstrated a positive relationship between oral and gastric $H$. pylori presence and periodontal disease.

Souto et al. [55] evaluated the presence of oral H. pylori among 56 periodontally healthy and 169 chronic periodontitis patients and found a statistically significant relationship between the presence of chronic periodontitis and bacterial oral colonization. Sambashivaiah et al. [52] found no relationship between periodontal disease and oral H. pylori .

Additionally, Butt et al. [56] also failed to demonstrate an association between the oral presence of $H$. pylori and gingival and periodontal health in 78 patients with dyspeptic complaints. Namiot et al. [57] investigated the relationship between oral 
hygiene status and oral $H$. pylori presence among 155 dyspeptic patients, but they did not find a relationship. Bali et al. [51] included 124 dyspeptic patients in their study. Sixty patients were found to be gastric H. pylori positive and 64 patients were found to be gastric $H$. pylori negative. The researchers did not indicate any relationship between gastric $H$. pylori presence and oral hygiene status. Liu et al. [19] found a positive relationship between H. pylori presence in dental plaque and oral hygiene status. They stated that all of the patients who had H. pylori in their dental plaque samples were irregularly brushing their teeth [58]. Another study [3] was conducted among Chinese children aged between 3-6 years in order to determine the presence of $H$. pylori in the dental plaque samples and its association with dental caries and oral hygiene habits. In this study, a significant relationship was found between oral H. pylori presence and dental caries. The investigators indicated that the oral cavity may be a reservoir for the bacterium; thus, $H$. pylori in dental plaque may play a role in the formation of dental caries, and poor oral hygiene may be a risk factor for $H$. pylori survival in the oral cavity. Few studies have evaluated the relationship between caries and $H$. pylori in the literature. Berroteran et al [59] investigated whether there was a relationship between oral $H$. pylori presence and caries in 32 dyspeptic and 20 asymptomatic healthy subjects. The results did not show a correlation between caries and the presence of oral H. pylori . Also, they found that patients with poor oral hygiene and periodontal status had a similar prevalence of $H$. pylori to patients with good-to moderate dental hygiene.

Banatvala et al. [61] found that $58 \%$ of 19 healthy children had H. pylori in their dental plaque samples, but no relationship was demonstrated between oral $H$. pylori presence and caries. Kolho et al. [58] compared gastric H. pylori positive and negative children in terms of caries presence and found no significant difference in caries prevalence between the two groups. The researchers reported that gastric H. pylori positive children may have a higher risk of caries development due to medical problems. Wickelhous et al. [60] found no association between H. pylori presence and Streptococcus mutans count in the dental plaque, but the investigators reported that H. pylori in the dental plaque was found at a higher rate in patients with low lactobacilli counts.

\section{Conclusion}

H. pylori is a highly pathogenic bacteria that is responsible for gastritis and peptic ulcer formation and causes stomach cancer. For this reason, it is very important to prevent the spread of bacteria among people and the success of eradication treatment must be ensured. Dental plaque is an oral biofilm layer formed on the tooth surface and contains millions of microorganisms. Since H. pylori has been isolated on the dental plaque, an answer has been sought as to whether this bacterium poses a risk in terms of re-infection of the gastrium. Poor oral hygiene and dental plaque accumulation may lead to the proliferation of $H$. pylori as a microaerophilic feature that can cause infections. For this reason, patients should maintain good oral care and have regular dental visits in order to prevent possible gastric colonizations.

\section{Acknowledgment}

No external funding source was obtained for this study. Also, there were no conflicts of interest.

\section{References}

1. Silva DG, Tinoco EM, Rocha GA, Rocha AM, Guerra JB, et al. (2010) Helicobacter pylori transiently in the mouth may participate in the transmission of infection. Mem Inst Oswaldo Cruz 105(5): 657-660.

2. Assumpcao MB, Martins LC, Melo Barbosa HP, Barile KA, de Almeida SS, et al. (2010) Helicobacter pylori in dental plaque and stomach of patients from Northern Brazil. World J Gastroenterol 16(24): 3033-3039.

3. Liu Y, Lin H, Bai Y, Qin X, Zheng X, et al. (2008) Study on the relationship between Helicobacter pylori in the dental plaque and the occurrence of dental caries or oral hygiene index. Helicobacter 13(4): 256-260.

4. Senbanjo IO, Oshikoya KA, Njokanma OF (2014) Helicobacter pylori associated with breastfeeding, nutritional status and recurrent abdominal pain in healthy Nigerian children. J Infect Dev Ctries 8(4): 448-453.

5. Chaudhry S, Iqbal HA, Khan AA, Izhar M, Butt AK, et al. (2008) Helicobacter pylori in dental plaque and gastric mucosa: correlation revisited. J Pak Med Assoc 58(6): 331-334.

6. Brown LM (2000) Helicobacter pylori: epidemiology and routes of transmission. Epidemiol Rev 22(2): 283-297.

7. Ahmed KS, Khan AA, Ahmed I, Tiwari SK, Habeeb MA, et al. (2006) Prevalence study to elucidate the transmission pathways of Helicobacter pylori at oral and gastroduodenal sites of a South Indian population. Singapore Med J 47(4): 291-296.

8. Luman W (2002) Helicobacter pylori transmission: Is it due to kissing? J R Coll Physicians Edinb 32: 275-279.

9. Al Sayed A, Anand PS, Kamath KP, Patil S, Preethanath RS, et al. (2014) Oral cavity as an Extragastric Reservoir of Helicobacter pylori. ISRN Gast (1): 1-16.

10. Torcatoru A, Roman I (2010) The oral presence of helicobacter pylori and its implications on oral condition and gastric pathology. AMT Jour 2(1): 259-261.

11. Dowsett SA, Archila L, Segreto VA, Gonzalez CR, Silva A, et al. (1999) Helicobacter pylori infection in indigenous families of Central America: serostatus and oral and fingernail carriage. J Clin Microbiol 37(8): 24562460 .

12. Chaudhry S, Idrees M, Izhar M, Butt AK, Khan AA (2011) Simultaneous amplification of two bacterial genes: more reliable method of Helicobacter pylori detection in microbial rich dental plaque samples. Curr Microbiol 62(1): 78-83.

13. Burgers R, Schneider Brachert W, Reischl U, Behr A, Hiller KA, et al. (2008) Helicobacter pylori in human oral cavity and stomach. Eur J Oral Sci 116(4): 297-304.

14. Altındiş S, Altındiş M, Özdemir M, Ellidokuz E, Uslan I, et al. (2010) Dispeptik yakınmalı hastaların dental plak ve mide biyopsi örneklerinde helicobacter pylori'nin real time-PCR ile araştırılması. SDÜ Tıp Fak Derg 17(2): 1-7.

15. Sayed MM, Ibrahim WA, Abdel bary SA, Abdelhakam SM, El Masry S, et al. (2011) Salivary PCR detection of Helicobacter pylori DNA in Egyption patients with dyspepsia. The Egyption J of Med Hum Gen 12(1): 211216.

16. Bharath TS, Reddy MS, Dhanapal R, Raj Kumar NG, Neeladri Raju P, et al. (2014) Molecular detection and correlation of Helicobacter pylori in dental plaque and gastric biopsies of dyspeptic patients. J Oral Maxillofac Pathol 18(1): 19-24.

17. Valdez Gonzales JA, Mares Moreno PC, Kawolik MJ, Valdez Gonzales JA, Gonzales Salazar F, et al. (2014) Detection of Helicobacter pylori in dental plaque of Mexican children by real-time PCR. Health J 6(4): 231235 .

18. Rasmussen LT, Labio RW, Gatti LL, Silva LC, Queiroz VF, et al. (2010) Helicobacter pylori detection in gastric biopsies, saliva and dental 
plaque of Brazilian dyspeptic patients. Mem Inst Oswaldo Cruz 105(3): 326-330.

19. Liu Y, Yue H, Li A, Wang J, Jiang B, et al. (2009) An epidemiologic study on the correlation between oral Helicobacter pylori and gastric $\mathrm{H}$. pylori. Curr Microbiol 58(5): 449-453.

20. Tiwari SK, Khan AA, Ahmed KS, Ahmed I, Kauser F, et al. (2005) Rapid diagnosis of Helicobacter pylori infection in dyspeptic patients using salivary secretion: a non-invasive approach. Singapore Med J 46(5): 224-228.

21. Bickley J, Owen RJ, Fraser AG, Pounder RE (1993) Evaluation of the polymerase chain reaction for detecting the urease $\mathrm{C}$ gene of Helicobacter pylori in gastric biopsy samples and dental plaque. J Med Microbiol 39(5): 338-344.

22. Hardo PG, Tugnait A, Hassan F, Lynch DA, West AP, et al. (1995) Helicobacter pylori infection and dental care. Gut 37(1): 44-46.

23. Li C, Musich PR, Ha T, Ferguson DA, Patel NR, et al. (1995) High prevalence of Helicobacter pylori in saliva demonstrated by a novel PCR assay. J Clin Pathol 48(7): 662-666.

24. Song Q Haller B, Ulrich D, Wichelhaus A, Adler G, et al. (2000) Quantitation of Helicobacter pylori in dental plaque samples by competitive polymerase chain reaction. J Clin Pathol 53(3): 218-222.

25. Song Q, Lange T, Spahr A, Adler G, Bode G (2000) Characteristic distribution pattern of Helicobacter pylori in dental plaque and saliva detected with nested PCR. J Med Microbiol 49(4): 349-353.

26. Suzuki N, Yoneda M, Naito T, Iwamoto T, Masuo Y, et al. (2008) Detection of Helicobacter pylori DNA in the saliva of patients complaining of halitosis. J Med Microbiol 57(12): 1553-1559.

27. Tiomny E, Arber N, Moshkowitz M, Peled Y, Gilat T (1992) Halitosis and Helicobacter pylori. A possible link? J Clin Gastroenterol 15(3): 236-237.

28. Serin E, Gumurdulu Y, Kayaselcuk F, Ozer B, Yilmaz U, et al. (2003) Halitosis in patients with Helicobacter pylori-positive non-ulcer dyspepsia: an indication for eradication therapy? Eur J Intern Med 14(1): 45-48.

29. Katsinelos P, Tziomalos K, Chatzimavroudis G, Vasiliadis T, Katsinelos T, et al. (2007) Eradication therapy in Helicobacter pylori-positive patients with halitosis: long-term outcome. Med Princ Pract 16(2): 119-123.

30. Chen X, Tao DY, Li Q Feng XP (2007) The relationship of halitosis and Helicobacter pylori. Gastroenterol 16(3): 236-238.

31. Schubert TT, Schubert AB, Ma CK (1992) Symptoms, gastritis, and Helicobacter pylori in patients referred for endoscopy. Gastrointest Endosc 38(3): 357-360.

32. Norfleet RG (1993) Helicobacter halitosis. J Clin Gastroenterol 16(3): 274.

33. Gasbarrini A, Ojetti V, Pitocco D, De Luca A, Franceschi F, et al. (1998) Helicobacter pylori infection in patients affected by insulin-dependent diabetes mellitus. Eur J Gastroenterol Hepatol 10(6): 469-472.

34. Werdmuller BF, van der Putten TB, Balk TG, Lamers CB, Loffeld RJ (2000) Clinical presentation of Helicobacter pylori-positive and -negative functional dyspepsia. J Gastroenterol Hepatol 15(5): 498-502.

35. Birek C, Grandhi R, Mc Neill K, Singer D, Ficarra G, et al. (1999) Detection of Helicobacter pylori in oral aphthous ulcers. J Oral Pathol Med 28(5): 197-203.

36. Porter SR, Barker GR, Scully C, Macfarlane G, Bain L (1997) Serum IgG antibodies to Helicobacter pylori in patients with recurrent aphthous stomatitis and other oral disorders. Oral Surg Oral Med Oral Pathol Oral Radiol Endod 83(3): 325-328.

37. Riggio MP, Lennon A, Wray D (2000) Detection of Helicobacter pylori DNA in recurrent aphthous stomatitis tissue by PCR. J Oral Pathol Med 29(10): 507-513
38. Shimoyama T, Horie N, Kato T, Kaneko T, Komiyama K (2000) Helicobacter pylori in oral ulcerations. J Oral Sci 42(4): 225-229.

39. Avcu N, Avcu F, Beyan C, Ural AU, Kaptan K, et al. (2001) The relationship between gastric-oral Helicobacter pylori and oral hygiene in patients with vitamin B12-deficiency anemia. Oral Surg Oral Med Oral Pathol Oral Radiol Endod 92(2): 166-169.

40. Leimola Virtanen R, Happonen RP, Syrjanen S (1995) Cytomegalovirus (CMV) and Helicobacter pylori (HP) found in oral mucosal ulcers. J Oral Pathol Med 24(1): 14-17.

41. Mravak Stipetic M, Gall Troselj K, Lukac J, Kusic Z, Pavelic K, et al. (1998) Detection of Helicobacter pylori in various oral lesions by nested polymerase chain reaction (PCR). J Oral Pathol Med 27(1): 1-3.

42. Singh K, Kumar S, Jaiswal MS, Chandra M, Singh M (1998) Absence of Helicobacter pylori in oral mucosal lesions. J Indian Med Assoc 96(6): 177-178.

43. Iamaroon A, Chaimano S, Linpisarn S, Pongsiriwet $S$, Phornphutkul $\mathrm{K}$ (2003) Detection of Helicobacter pylori in recurrent aphthous ulceration by nested PCR. J Oral Sci 45(2): 107-110.

44. Adler I, Denninghoff VC, Alvarez MI, Avagnina A, Yoshida R, et al. (2005) Helicobacter pylori associated with glossitis and halitosis. Helicobacter 10(4): 312-317.

45. Gall Troselj K, Mravak Stipetic M, Jurak I, Ragland WL, Pavelic J (2001) Helicobacter pylori colonization of tongue mucosa increased incidence in atrophic glossitis and burning mouth syndrome (BMS). J Oral Pathol Med 30(9): 560-563.

46. Ierardi E, Amoruso A, La Notte T, Francavilla R, Castellaneta S, et al. (1998) Halitosis and Helicobacter pylori: a possible relationship. Dig Dis Sci 43(12): 2733-2737.

47. Elsheikh MN, Mahfouz ME (2005) Prevalence of Helicobacter pylori DNA in recurrent aphthous ulcerations in mucosa-associated lymphoid tissues of the pharynx. Arch Otolaryngol Head Neck Surg 131(9): 804808.

48. Mansour Ghanaei F, Asmar M, Bagherzadeh AH, Ekbataninezhad S (2005) Helicobacter pylori infection in oral lesions of patients with recurrent aphthous stomatitis. Med Sci Monit 11(12): 576-579.

49. Al Asqah M, Al Hamoudi N, Anil S, Al Jebreen A, Al Hamoudi WK (2009) Is the presence of Helicobacter pylori in dental plaque of patients with chronic periodontitis a risk factor for gastric infection? Can J Gastroenterol 23(3): 177-179.

50. Anand PS, Nandakumar K, Shenoy KT (2006) Are dental plaque, poor oral hygiene, and periodontal disease associated with Helicobacter pylori infection? J Periodontol 77(4): 692-698.

51. Bali D, Rosamma J, Bali A (2010) The Association of dental plaque and Helicobacter Pylori infection in dyspeptic patients undergoing endoscopy J Clin Diagn Res 4(1): 3614-3621.

52. Sambashivaiah S, Bilichodmath S, Nanjaiah N, Kulal R(2011) Helicobacter Pylori in periodontal pockets of chronic periodontitis patients with and without type II diabetes mellitus: a randomized controlled trial. Microbiol Res 3(2): 45-48.

53. Zaric S, Bojic B, Jankovic L, Dapcevic B, Popovic B, et al. (2009) Periodontal therapy improves gastric Helicobacter pylori eradication. J Dent Res 88(10): 946-950.

54. Silva DG, Stevens RH, Macedo JM, Albano RM, Falabella ME, et al. (2010) Presence of Helicobacter pylori in supragingival dental plaque of individuals with periodontal disease and upper gastric diseases. Arch Oral Biol 55(11): 896-901.

55. Souto R, Colombo AP (2008) Detection of Helicobacter pylori by polymerase chain reaction in the subgingival biofilm and saliva of nondyspeptic periodontal patients. J Periodontol 79(1): 97-103.

56. Butt AK, Khan AA, Izhar M, Alam A, Shah SW, et al. (2002) Correlation 
of Helicobacter pylori in dental plaque and gastric mucosa of dyspeptic patients. J Pak Med Assoc 52(5): 196-200.

57. Namiot DB, Leszczynska K, Namiot Z, Chilewicz M, Bucki R, et al. (2010) The occurrence of Helicobacter pylori antigens in dental plaque; an association with oral health status and oral hygiene practices. Adv Med Sci 55(2): 167-171.

58. Kolho KL, Holtta P, Alaluusua S, Lindahl H, Savilahti E, et al. (2001) Dental caries is common in Finnish children infected with Helicobacter pylori. Scand J Infect Dis 33(11): 815-817.

59. Berroteran A, Perrone M, Correnti M, Cavazza ME, Tombazzi C, et al.
DOI: $10.26717 / B J S T R .2018 .08 .001635$

Damla Aksit Bicak. Biomed J Sci \& Tech Res

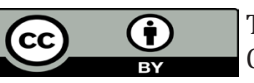

This work is licensed under Creative Commons Attribution 4.0 License

Submission Link: https://biomedres.us/submit-manuscript.php
(2002) Detection of Helicobacter pylori DNA in the oral cavity and gastroduodenal system of a Venezuelan population. J Med Microbiol 51(9): 764-770.

60. Wichelhaus A, Brauchli L, Song Q Adler G, Bode G (2011) Prevalence of Helicobacter pylori in the adolescent oral cavity: dependence on orthodontic therapy, oral flora and hygiene. J Orofac Orthop 72(3): 187195.

61. Banatvala N, Lopez Romero C, Owen RJ, Hurtado A, Abdi Y, et al. (1994) Use of the Polymerase Chain Reaction to detect Helicobacter pylori in the dental plaque of healthy and symptomatic individuals. Microb Ecoin Health and Serv 7(1): 1-8.

\begin{tabular}{ll} 
BIOMEDICAL & Assets of Publishing with us \\
RESEARCHES & - Global archiving of articles \\
& - Immediate, unrestricted online access \\
\hline
\end{tabular}

